\begin{tabular}{c} 
Brazilian Journal \\
of Chemical \\
Engineering \\
\hline
\end{tabular}

ISSN 0104-6632

Printed in Brazil

www.abeq.org.br/bjche

Vol. 32, No. 04, pp. 941 - 947, October - December, 2015

dx.doi.org/10.1590/0104-6632.20150324s20140252

\title{
MODELING OF THE EXTRACTION PROCESS OF TEA SEED OIL WITH SUPERCRITICAL CARBON DIOXIDE
}

\author{
Jinan Feng ${ }^{1}$, Huaping Lei ${ }^{1 *}$ and Fahuan $\mathrm{Ge}^{2}$ \\ ${ }^{1}$ Department of Chemistry and Life Science, Xiangnan University, Chenzhou, 423000, China. \\ E-mail: audenlei@163.com \\ ${ }^{2}$ School of Pharmaceutical Sciences, Sun Yat-Sen University, Guangzhou, 510275, PR China. \\ (Submitted: December 24, 2014 ; Revised: February 10, 2015 ; Accepted: February 11, 2015)
}

\begin{abstract}
The kinetics of the extraction of tea seed oil with supercritical $\mathrm{CO}_{2}$ was studied. A kinetic model of the extraction of tea seed oil using supercritical $\mathrm{CO}_{2}$ was developed on the basis of the differential mass balance to simulate the extraction process. The model could simulate the distribution of the solute concentration in $\mathrm{CO}_{2}$ inside the extraction bed as a function of extraction time and height of the extraction bed. The model could also simulate of the solute concentration in $\mathrm{CO}_{2}$ at the outlet of the extractor as a function of time. The effects of the parameters such as pressure and temperature on extraction yield and the process were investigated through the model. This model could simulate satisfactorily the process of extraction with an error between simulation data and experimental data of less than $10 \%$.

Keywords: Supercritical $\mathrm{CO}_{2}$ extraction; Kinetics; Simulation; Tea seed oil.
\end{abstract}

\section{INTRODUCTION}

Camellia oleifera is the key edible oil tree growing specifically in the south of China. Tea seed oil, a high quality edible oil, is obtained from Camellia oleifera seeds. Tea seed oil contains more than $84 \%$ unsaturated fatty acids, such as oleic acid, linoleic acid, and linolenic acid, and is characterized by its unique flavor, durable storage, and ease of absorption into the body (Ma et al., 2011). It is one of the four edible tree oils (the other three being palm oil, olive oil, coconut oil).

Supercritical $\mathrm{CO}_{2}$ extraction is a new and green technology for extraction and separation with several virtues such as high efficiency, short extraction time, low operation temperature, less pollution etc.. It has been widely applied in fields such as food, flavor, medicine, etc. Supercritical $\mathrm{CO}_{2}$ extraction of tea seed oil have been performed by several researchers to study the effects of parameters such as pressure, temperature, extraction time and modifier on the yield and composition of the oil (Rajaei et al., 2005; $\mathrm{Xu}$ et al., 2010; Zhong et al., 2001; Zhou et al., 2012). Based on our literature survey, no work has been done on the mathematical modeling of the extraction process. Compared with the applied research, the research on the kinetics and mechanisms of dissolution and mass transfer in the extraction of tea seed oil is thus less well developed.

There are three kinds of kinetic models for supercritical $\mathrm{CO}_{2}$ extraction: empirical kinetic models, kinetic models based on heat transfer and kinetic models based on differential mass balance (Reverchon and Polette, 1996). The simple empirical equation proposed by Naik et al. (1989) represents the extraction yield as a function of extraction time in terms of a Langmuir gas adsorption isotherm. Roy and Goto (1996) set up an empirical kinetic model when they extracted oils from ginger root using supercritical fluid. However, in the empirical kinetic

*To whom correspondence should be addressed 
model the mechanisms of dissolution and mass transfer are not taken into account (Subra et al., 1998; Papamichail et al., 2000). Generally the empirical kinetic model is applicable to interpolation not to extrapolation.

In the kinetic model based on heat transfer, the SFE is treated as a heat transfer phenomenon. Each particle of the solute is considered to be a hot sphere cooling in a uniform medium (Li and Qiu, 2007). The model assumes that particles are spherical (Reverchon, et al., 1993; Esquivel, et al., 1999), which can produce a very big error when the shape of the particles differs greatly from spherical. Secondly, in the models only the effect of diffusion in the particles on mass transfer is taken into account. Thus, the model will not be applicable if substantial mass transfer resistance exists in the fluid phase (Wei et al., 2003).

The kinetic model based on differential mass balance centers on mass transfer and can solve the distribution of solute concentration in the fluid phase as a function of height of the extraction bed and extraction time (Reverchon and Marrone, 2001). Therefore, the model fits much research data on the extraction process. Reverchon used the kinetic model based on differential mass balance to model supercritical extraction of clove bud essential oil and sage oil (Reverchon, 1996; Reverchon and Marrone, 1997). However, there are still lots of assumptions in the kinetic models based on the differential mass balance equation, such as particle shape. Some models need to calculate the mass transfer coefficient for comparison with experimental results.

In this paper an improved kinetic model based on the differential mass balance equation is described for the kinetics of extracting tea seed oil with supercritical $\mathrm{CO}_{2}$, which overcomes the shortcomings listed above. Compared with general models based on differential mass balance, in this model the shape of particles and mass transfer in the solid phase are not taken into account, which facilitates calculation and makes the model more universal. If an artificial neural network were combined with this model, it would predict the extraction yields under other extraction conditions and could play an important role in the scale-up design of extraction process (Fullana et al., 1999).

\section{EXPERIMENTAL APPARATUS AND METHODOLOGY}

\section{Experimental Apparatus}

The experimental apparatus (Huaan Supercritical Fluid Extraction Company, Jiangsu Province, China) has an extractor vessel of $1000 \mathrm{~cm}^{3}$ and two separators, as shown in Figure 1. Pressure and temperature could be controlled in the extractor and the separators. Operations can be carried out in a closed loop for carbon dioxide, which is recycled as a gas from the last expansion vessel to the pump inlet.

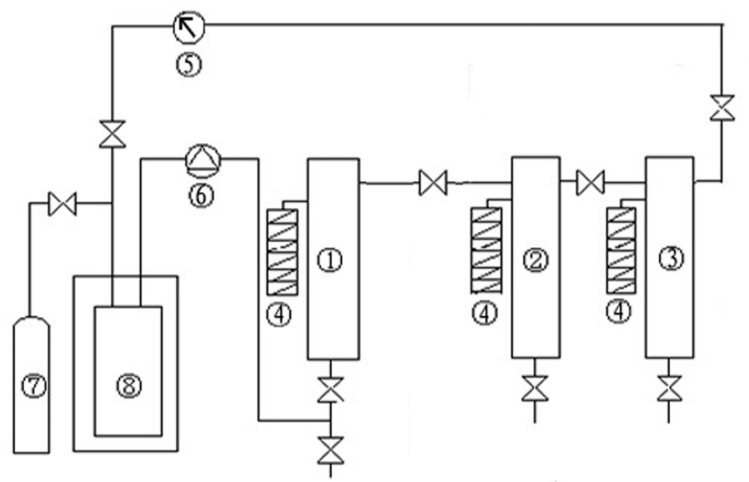

Figure 1: Supercritical $\mathrm{CO}_{2}$ extraction apparatus: (1) extractor; (2) separator I; (3) separator II; (4) heat exchanger; (5) rotameter; (6) high pressure pump; (7) $\mathrm{CO}_{2}$ cylinder; (8) $\mathrm{CO}_{2}$ tank.

\section{Supercritical $\mathrm{CO}_{2}$ Extraction}

The samples were ground and sieved to the same granularity of 20 to 40 meshes. The samples were fed in the extractor and the air in the extractor removed by $\mathrm{CO}_{2}$. The desired temperatures of extractor, separators, $\mathrm{CO}_{2}$ tank and heat exchanger were maintained by water baths, respectively. Liquid $\mathrm{CO}_{2}$ from the $\mathrm{CO}_{2}$ tank was pumped into the extractor with a high pressure pump. Upon reaching the desired pressure in the extractor and the separators, the extraction started. The extracts were discharged from the separator I and the separator II every 20 minutes, which were weighed.

\section{MATHEMATICAL MODEL}

Many factors affect the extraction process. To simplify the mathematical model, following hypotheses are needed: (a) temperatures and pressures in all parts of the extraction bed are uniform, dissolution and diffusion are carried out in isothermal and isobaric conditions; (b) the velocity and the density of the supercritical $\mathrm{CO}_{2}$ are constant along the extraction bed; (c) although several components are involved in the extract, their mass transfer behaviors are assumed to be similar, the extract is considered as a single component that is called the "solute" in 
this paper.

According to the above hypotheses, the differential mass balance of the solute along the extraction bed is given by:

$\rho \varepsilon \frac{\partial y}{\partial t}+\rho \mathrm{u} \frac{\partial y}{\partial z}-\rho \varepsilon \mathrm{D}_{\mathrm{ax}} \frac{\partial^{2} y}{\partial z^{2}}=J$

In Eq. (1), $J$ represents the rate of solute mass transfer from the outer surfaces of seeds to the fluid per unit of bed volume. $J$ will be written in terms of a product of the overall mass transfer coefficient, K, and the specific mass transfer area, A. So, KA will be the mass transfer rate per unit driving force. Since the driving force is $y^{*}-y, J$ can be written as

$$
J=\mathrm{KA}\left(y^{*}-y\right)
$$

The concentration of the oil in the fluid at the entrance of the extractor is zero. It is assumed that $y_{i}$ is the concentration of the oil at the outlet of the extractor at $t=t_{i}$. According to the relationship of mass conservation in the extraction bed, the expression for $y_{i}$ will be written as:

$y_{i}=\frac{(d q / d t)_{t_{i}}}{\mathrm{Q}} \mathrm{q}_{\mathrm{s}}$

where $(d q / d t)$ is the rate of oil extraction at time $t_{i}$. The value used for KA in the calculations is obtained from the following relationships:

$$
y_{i} \mathrm{Q}=J_{i} \mathrm{~V}
$$

$$
(\mathrm{KA})_{i}=\frac{\mathrm{Q} / \mathrm{V}}{\left(y^{*} / y_{i}-1\right)}
$$

$y^{*}$ is the equilibrium concentration of the solute in $\mathrm{CO}_{2}$ at a certain temperature and pressure. According to Eq. (2), Eq. (3) and Eq. (5) the mass transfer rate, $J$, can be calculated. Thus, Eq. (1) can be solved using numerical integration with the following initial and boundary conditions.

$$
\begin{aligned}
& \left.y\right|_{z, t=0}=0 \\
& \left.\mathrm{u} y\right|_{z=0, t}-\varepsilon D_{a x}\left(\frac{\partial y}{\partial z}\right)_{z=0, t}=0
\end{aligned}
$$

$$
\left(\frac{\partial y}{\partial z}\right)_{z=h, t}=0
$$

\section{MODEL PARAMETERS}

The average molecular weight of tea seed oil was obtained from Ma et al. (2011). The density of supercritical $\mathrm{CO}_{2}$ fluid was calculated using the Equations of State (EOS) software programmed by David Bush from the Georgia Institute of Technology. The Lucas method was used for viscosity calculation (Poling et al., 2001). The axial dispersion coefficient of the solute in supercritical solvent was given by the correlation of Keat et al. (Liong et al., 1992):

$D_{a x}=2.42 \times 10^{-14} M^{-0.48} T / \mu$

And $y^{*}$ was given by the correlation of Valle and Aguilera (1988):

$$
y^{*}=\exp \left(40.361-18708 / T+2186840 / T^{2}\right) \rho^{10.724}
$$

\section{RESULTS AND DISCUSSION}

The values of the parameters for the experimental conditions are shown in Table 1 and the calculation and simulation parameters are shown in Figure 2, Figure 3 and Figure 4, at the temperature of $318 \mathrm{~K}$, pressures of $30 \mathrm{MPa}$ and $35 \mathrm{MPa}$, and a $\mathrm{CO}_{2}$ flow rate of $20 \mathrm{~L} / \mathrm{h}$, using an amount of feed of $200 \mathrm{~g}$. Because the pressure and the temperature for extraction of fatty oil are generally from $27 \mathrm{MPa}$ to $35 \mathrm{MPa}$ and from $308 \mathrm{~K}$ to $328 \mathrm{~K}$, respectively, we modeled the extraction at a temperature of $318 \mathrm{~K}$ and pressures of $30 \mathrm{MPa}$ and $35 \mathrm{MPa}$. As shown in Figure 2, the extraction rate was maximum at first and, after some time, decreased rather quickly both at $30 \mathrm{MPa}$ and 35 $\mathrm{MPa}$. This is in good agreement with the fact that, in the extraction process, the amounts of the oil extracted were equal in every interval at the beginning and then began to decrease. The extraction process consisted of two extraction regimes, a fast regime and a slow regime, respectively. In the fast regime, the extraction rate was nearly constant. In the slow regime, the extraction rate decreased rapidly. This may be because there was much oil on the surface of particles after grinding and the remaining oil was inside the particles. In the fast regime, the oil on the outside of the particles was easy to extract. The extraction was only affected by the diffusion resistance 
in the fluid. After the oil on the outside of the particles was extracted completely, it entered into the slow regime, in which the residual oil was inside of the particles. The extraction in the slow regime was affected by the diffusion resistance in the solid particles. Because the $\mathrm{CO}_{2}$ flow rate of $20 \mathrm{~L} / \mathrm{h}$ was small, the extraction time approached 4 hours. The extraction rate at $35 \mathrm{MPa}$ and $318 \mathrm{~K}$ was greater than that at $30 \mathrm{MPa}$ and $318 \mathrm{~K}$ because the solvent power of $\mathrm{CO}_{2}$ at $35 \mathrm{MPa}$ was much greater than that of $30 \mathrm{MPa}$. As shown in Table 1 , at $30 \mathrm{MPa}$ and $35 \mathrm{MPa}$, the $y^{*}$ values were $6.89 \mathrm{~g} / \mathrm{kg}$ and $9.38 \mathrm{~g} / \mathrm{kg}$, respectively.

Table 1: Values of the parameters for the experimental conditions.

\begin{tabular}{|c|c|c|c|c|c|}
\hline $\begin{array}{c}\text { Pressure } \\
(\mathbf{M P a})\end{array}$ & $\begin{array}{c}\text { Temperature } \\
\mathbf{( K )}\end{array}$ & $\begin{array}{c}\text { Density of } \\
\mathbf{C O}_{\mathbf{2}} \\
\left(\mathbf{k g} / \mathbf{m}^{\mathbf{3}}\right)\end{array}$ & $\begin{array}{c}\text { Viscosity of } \\
\mathbf{C O}_{\mathbf{2}} \\
\left(\mathbf{1 0}^{-\mathbf{5}} \mathbf{P a} / \mathbf{( s )}\right)\end{array}$ & $\begin{array}{c}\mathbf{D}_{\mathbf{a x}} \\
\left(\mathbf{1 0}^{-\mathbf{9}} \mathbf{m}^{\mathbf{2}} / \mathbf{s}\right)\end{array}$ & $\begin{array}{c}\boldsymbol{y}^{*} \\
(\mathbf{g} / \mathbf{k g})\end{array}$ \\
\hline 25 & 308 & 903 & 8.54 & 5.85 & 4.85 \\
25 & 318 & 858 & 7.94 & 6.49 & 4.54 \\
25 & 328 & 812 & 7.43 & 7.16 & 4.13 \\
30 & 308 & 930 & 9.21 & 5.42 & 6.65 \\
30 & 318 & 892 & 8.55 & 6.03 & 6.89 \\
30 & 328 & 851 & 8.03 & 6.62 & 6.83 \\
35 & 308 & 954 & 9.83 & 5.08 & 8.74 \\
35 & 318 & 918 & 9.11 & 5.66 & 9.38 \\
35 & 328 & 882 & 8.55 & 6.22 & 10.02 \\
40 & 308 & 973 & 10.40 & 4.80 & 10.80 \\
40 & 318 & 941 & 9.63 & 5.35 & 12.23 \\
40 & 328 & 908 & 9.03 & 5.90 & 13.68 \\
\hline
\end{tabular}

The distribution of the solute concentration in $\mathrm{CO}_{2}$ inside the extraction bed as a function of extraction time and height of the extraction bed is shown in Figure 3 . The solute concentration gradually increased along the height of the extraction bed. The maximum of the solute concentration was close to the solute concentration in the fluid at saturation, $y^{*}$. The solute con- centration gradually decreased along the extraction time, the curve being similar to the curve for extraction rate. The distribution of the solute concentration in $\mathrm{CO}_{2}$ inside the extraction bed as a function of extraction time and height of the extraction bed at 30 $\mathrm{MPa}$ and $318 \mathrm{~K}$ was only slightly different from that at $35 \mathrm{MPa}$ and $318 \mathrm{~K}$. The extraction at $35 \mathrm{MPa}$ and $318 \mathrm{~K}$ had a shorter extraction time and higher solute concentration inside the extraction bed. The solute concentration in the fluid at the outlet of the extractor increased from zero to the maximum in a few minutes, maintained it for a time and then gradually decreased, as shown in Figure 4. The experimental data and values predicted by the model are shown in Figure 5 and Figure 6 at each pressure and temperature, using an amount of feed of $200 \mathrm{~g}$. As shown in Figure 5, at $318 \mathrm{~K}$ the extraction yields increased along with the extraction pressure from $25 \mathrm{MPa}$ to $40 \mathrm{MPa}$, because the solvent power of $\mathrm{CO}_{2}$ increased along with the extraction pressure. As shown in Figure 6, the effect of temperature on the extraction at $30 \mathrm{MPa}$ was complex. The extraction yield at $318 \mathrm{~K}$ was higher than that at $308 \mathrm{~K}$ or $328 \mathrm{~K}$. On the one hand, as the temperature increases, the density of $\mathrm{CO}_{2}$ decreases. So the solvent power of $\mathrm{CO}_{2}$ and the extraction rate decrease. On the other hand, as the temperature increases, the dispersion coefficient increases, which facilitates the extraction. This is in accord with Reverchon and Marron (2001). There was a good agreement between the values predicted by the model and the experimental data, with an error between simulation data and the experimental data of less than $10 \%$. The model reflected well the effects of extraction pressure and extraction temperature on the extraction process and extraction yield.
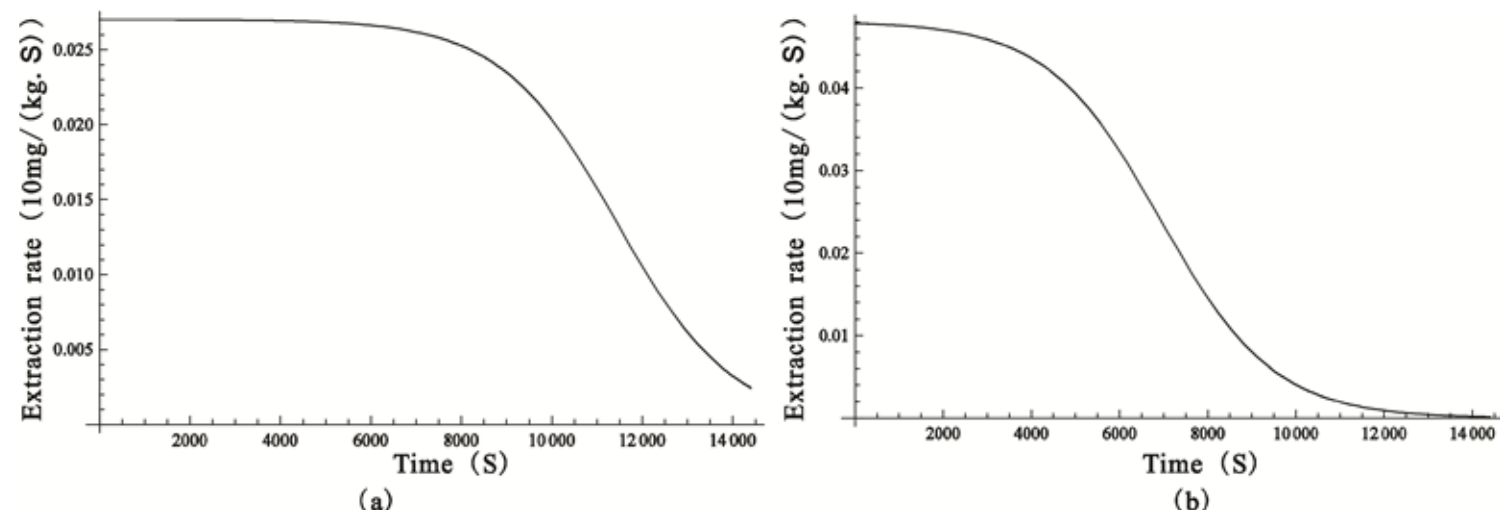

(b)

Figure 2: Curve for the extraction rate at (a) $30 \mathrm{MPa}$ and $318 \mathrm{~K}$ and (b) $35 \mathrm{MPa}$ and $318 \mathrm{~K}$. 


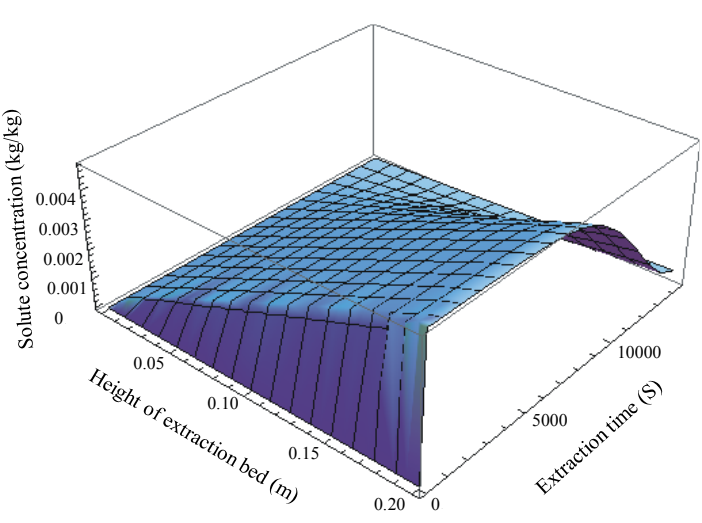

(a)

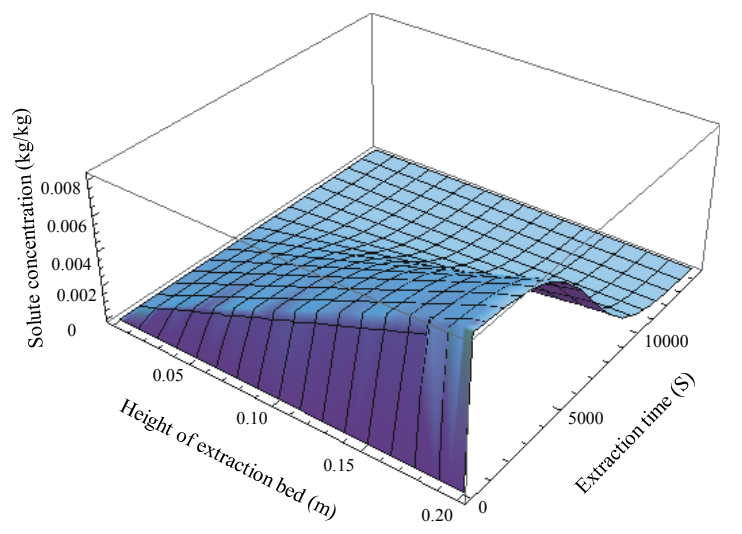

(b)

Figure 3: Simulation of the distribution of the solute concentration in $\mathrm{CO}_{2}$ inside the extraction bed as a function of extraction time and height of the extraction bed at (a) $30 \mathrm{MPa}$ and $318 \mathrm{~K}$ and (b) $35 \mathrm{MPa}$ and $318 \mathrm{~K}$.

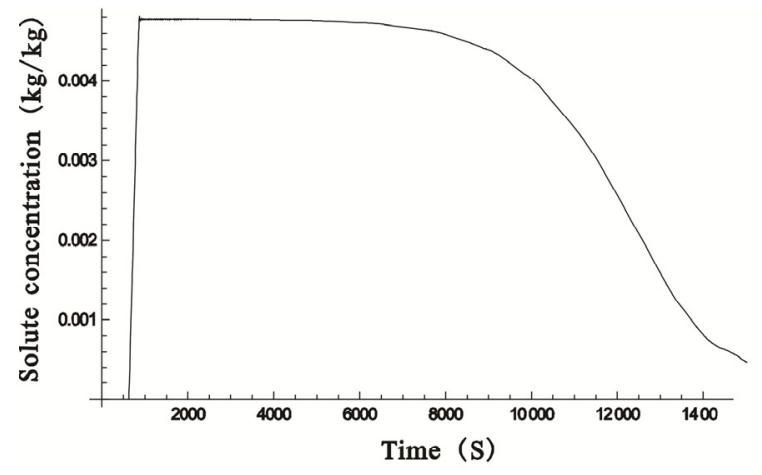

(a)

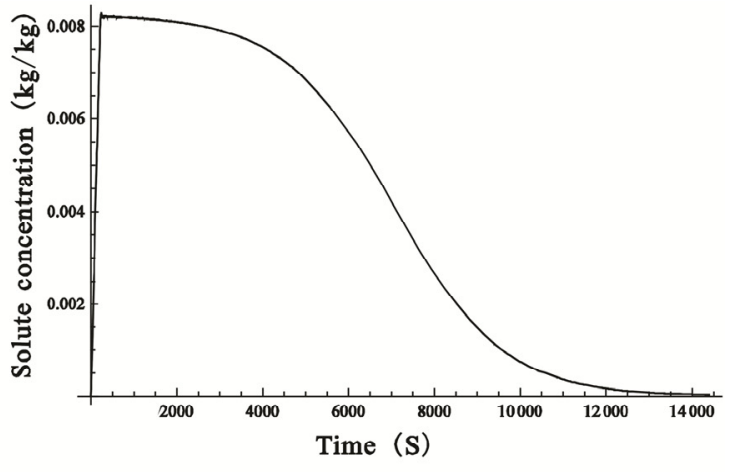

(b)

Figure 4: Simulation of the solute concentration in $\mathrm{CO}_{2}$ at the outlet of the extractor as a function of time at (a) $30 \mathrm{MPa}$ and $318 \mathrm{~K}$ and (b) $35 \mathrm{MPa}$ and $318 \mathrm{~K}$.

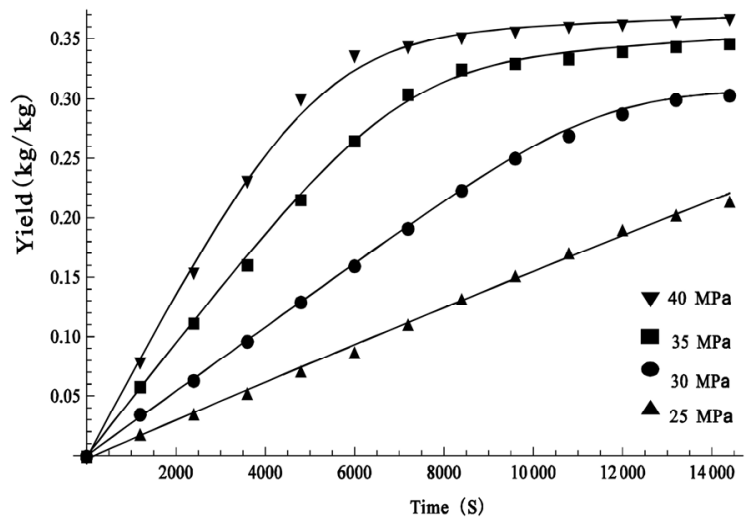

Figure 5: Effect of pressure on extraction at $318 \mathrm{~K}$ (Symbols-experimental data; Lines-simulations).

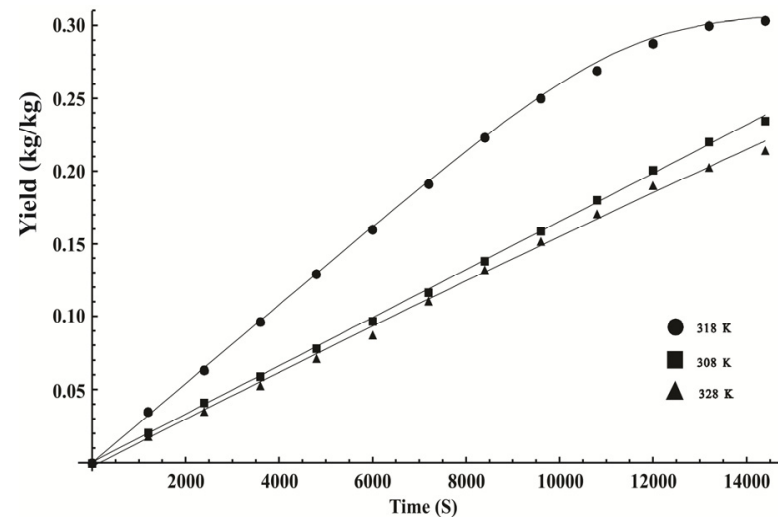

Figure 6: Effect of temperature on extraction at 30 $\mathrm{MPa}$ (Symbols-experimental data; Lines-simulations). 


\section{CONCLUSION}

The model based on differential mass balance adopted in this paper could simulate fairly well the extraction process, in particular the effects of extraction parameters on the extraction process and extraction yield. The model can be applied to simulating the extraction of other vegetable oils. The kinetic simulation of the extraction process can optimize the extraction parameters and aid in industrial scale-up. By inspecting the effects of each operating parameter on the extraction yield and process economy, the parameters can be optimized and, consequently industrial scale-up and optimized operation and control of the production are possible.

\section{ACKNOWLEDGEMENTS}

The authors thank The Natural Science Foundation of Hunan Province (20015JJ3111) and sci-tech plan project of Chenzhou city (2012cj125) for providing financial support to this project.

\section{NOMENCLATURE}

\begin{tabular}{|c|c|}
\hline A & specific mass transfer area $\left(\mathrm{m}^{-1}\right)$ \\
\hline $\mathrm{D}_{\mathrm{ax}}$ & axial dispersion coefficient $\left(\mathrm{m}^{2} / \mathrm{s}\right)$ \\
\hline$h$ & height of the extraction bed (m) \\
\hline$J$ & mass transfer rate $\left(\mathrm{kg} / \mathrm{m}^{3} . \mathrm{s}\right)$ \\
\hline K & mass transfer coefficient $\left(\mathrm{kg} / \mathrm{m}^{2} . \mathrm{s}\right)$ \\
\hline Q & $\mathrm{CO}_{2}$ mass flow rate $(\mathrm{kg} / \mathrm{s})$ \\
\hline $\mathrm{q}$ & mass of oil per unit weight of seeds $(\mathrm{kg} / \mathrm{kg})$ \\
\hline $\mathrm{q}_{\mathrm{s}}$ & mass of seeds in a differential run $(\mathrm{kg})$ \\
\hline $\mathrm{u}$ & superficial $\mathrm{CO}_{2}$ velocity $(\mathrm{m} / \mathrm{s})$ \\
\hline V & volume of the extractor $\left(\mathrm{m}^{3}\right)$ \\
\hline$y$ & $\begin{array}{l}\text { solute concentration in the fluid phase } \\
(\mathrm{kg} / \mathrm{kg})\end{array}$ \\
\hline$y^{*}$ & $\begin{array}{l}\text { solute concentration in the fluid at } \\
\text { saturation }(\mathrm{kg} / \mathrm{kg})\end{array}$ \\
\hline$z$ & axial coordinate $(\mathrm{m})$ \\
\hline$\rho$ & fluid density $\left(\mathrm{kg} / \mathrm{m}^{3}\right)$ \\
\hline$\varepsilon$ & bed void fraction \\
\hline
\end{tabular}

\section{REFERENCES}

Esquivel, M. M., Bernardo-Gil, M. G., King, M. B., Mathematical models for supercritical extraction of olive husk oil. J. Supercritical Fluids, 16, 43-48 (1999).

Fullana, M., Trabelsi, F. and Recasens, F., Use of neural net computing for statistical and kinetic modeling and simulation of supercritical fluid extractors. Chemical Engineering Science, 54, 5845-5862 (1999).

Li, C., Qiu, T. Q., Kinetic modeling of supercritical fluid extraction of flavonoid compounds from Cedrela Sinensis leaves. Chemistry \& Bioengineering, 24(3), 21-23 (2007).

Liong, K. K., Wells, P. A. and Foster, N. R., Diffusion of fatty acid esters in supercritical carbon dioxide. Ind. Eng. Chem. Res., 31(1), 390-399 (1992).

Ma, J., Ye, H., Rui, Y., Chen, G. and Zhang, N., Fatty acid composition of Camellia oleifera oil. Journal of Consumer Protection and Food Safety, 6(1), 9-12 (2011).

Naik, S. N., Lentz, H., Maheshwari, R. C., Extraction of perfumes and flavours from plant materials with liquid carbon dioxide under liquid-vapour equilibrium conditions. Fluid Phase Equilibria, 49(1), 115-126(1989).

Papamichail, I., Louli, V., Magoulas, K., Supercritical fluid extraction of celery seed oil. J. Supercritical Fluids, 18, 213-226 (2000).

Poling, B. E., Prausnitz, J. M. and Connell, J. P. O., The Properties of Gases and Liquids. McGraw-Hill, New York (2011).

Rajaei, A., Barzegar, M. and Yamini, Y., Supercritical fluid extraction of tea seed oil and its comparison with solvent extraction. European Food Research and Technology, 220(3-4), 401-405 (2005).

Reverchon, E., Donsi, G., Osseo, L. S., Modeling of supercritical fluid extraction from herbaceous matrices. Ind. Eng. Chem. Res., 32, 2721-2726 (1993).

Reverchon, E., Mathematical modeling of supercritical extraction of sage oil. AIChE Journal, 42(6), 1765-1771(1996).

Reverchon, E. and Polette, M., Mathematical modeling of supercritical $\mathrm{CO}_{2}$ fraction of flower concretes. Chemical Engineering Science, 51(15), 3741-3753 (1996).

Reverchon, E. and Marrone, C., Supercritical extraction of clove bud essential oil isolation and mathematical modeling. Chem. Eng. Sci., 52(20), 3421-3428 (1997).

Reverchon, E., Marrone, C., Modeling and simulation of supercritical $\mathrm{CO}_{2}$ extraction of vegetable oils. J. Supercritical Fluids, 19, 161-175 (2001).

Roy, C. and Goto, M., Supercritical fluid extraction oils from ginger root. Ind. Eng. Chem., 35, 607-611 (1996).

Subra, P., Castellani, S., Jestin, P., Aoufi, A., Extractionof $\beta$-carotene with supercritical fluids: Experimental and modeling. J. Supercritical Fluids, 12, 
261-269 (1998).

Valle, J. M. and Aguilera, J. M., An improved equation for predicting the solubility of vegetable oils in supercritical $\mathrm{CO}_{2}$. Ind. Eng. Chem. Res., 27(8), 1551-1553 (1988).

Wei, Y., Liu, X., Zhang, X. and Li, Z., Review on review of modeling of supercritical fluid extraction of solid substances. Journal of Chemical Industry \& Engineering, 24(1), 19-22 (2003).

Xu, J., Zhong, H., Liu, N., Long, Q. and Li, Z., Effect of roasting conditions on quality of oil-tea camellia seed oil extracted by supercritical $\mathrm{CO}_{2}$. China Oils and Fats, 35(6), 13-15 (2010).

Zhong, H., Wan, C. and Xie, B., The effect of supercritical $\mathrm{CO}_{2}$ extraction condition on the quality of oil-tea Camellia seed oil. Journal of the Chinese Cereals and Oils Association, 16(1), 9-13 (2001).

Zhou, Y., Gu, C. and Gu, H., Supercritical $\mathrm{CO}_{2}$ extraction of tea seed oil from Camellia seeds and composition analysis of tea seed oil extracts. Advanced Materials Research, 538-541, 2372-2376 (2012). 